research, for he says that the introduction to industrial research is best conducted in the industrial research laboratory itself.

The final address on selectivity in research is packed with thoughts that are of great general interest, not only in industrial reseurch but also in government or governmentsponsored research and development. The first basic problem is that in the United States research and devclopment in the industrial field only incroase at 10 per cent per year in dollars, whereas resoarch and development for the country as a whole grow at a rate of 20 per cont. The 10 per cent barely copos with the normal increase in costs and in salaries. In these circumstances, this mouns that an industrial laboratory has to try to becomo more productive and this can only be dono by a much more critical selection of projects. Fashion in research is attacked vigorously and a slavish following of fashion without good reason is reckoned to be one of the bast ways of decreasing productivity. For cxample, Dr. Suits considers research into lasers, and particularly their applications, is a ficld where far too much research has been done without there being a prior appreciation of the value of the application of research. Another danger is to try to kecp a finger in every pie as a kind of insurance policy. Dr. Suits considers this a waste of money and talent. Ho is surprisingly critical of the attempts to inject science into those industries that have been around virtually for centuries. What can be done in those industries has already bren done. The problems involved in the support of big science come in for some scathing criticism too. Bigness is what matters rather than the eriterion as to whethor it is good scienco too. Even more surprising is the analysis of the situation where the research venture is completely successful but when this point is roached no one can find an application for the knowledge so acquired. Dr. Suits admits in his speech that his tongue is somotimes in his cheek in making these remarks; nevertheless the questioning is very necessary at present not only in the United States but in Britain as well. This is a volume to be read with great interust by everyone interested in the management of rescarch and development and also in engineering.

HARRY MelVILI.F

\section{SOCIAL IMPLICATIONS OF NUCLEAR POWER}

\section{A Peril and a Hope}

The Scientists' Movement in America, 1945-47. By Alice Kimball Smith. Pp. xiv +591. (Chicago and London: The University of Chicago Press, 1965.) 10 dollars; $72 s$.

A PERLL and a Hope is an excossivoly long and detailed $A$ account of what is doscribed as the scientists' movement in America, 1945-47. It is concerned more especially with the way in which scientists connocted with the development of tho atomic bomb and with nucloar powor awoke to the social and political implications of their work and sought to influence national policy. Its scope is, in timo at least, moro limited than that of Robert Gilpin, in American Scientists and Nuclear Weapons Policy, but it is not limited to questions of the uso of nuoloar weapons. It is nearer in seope to $\mathbf{A}$. $\mathrm{H}$. Compton's Atomic Quest, which at some points it amplifies and corrects. The real interest and value of the book lie in its contribution to the entinuing discussion of the influenes of scienco and of scientists on publie policy, the limits of that infuence and the mecharism. by which advice is most effectively tendered. Much of it is strictly relevant to conditions in the United States, and here tho oxcessivo detail makcs it more difficult to bring out the relevance of the experience described to conditions in Britain. Even so, it should contribute to a olearer understanding of that oxperience, and the book includes, moreover, as appendixes, the important Jeffries report of Novomber 1944 on the prospects of nucleonies and the French report of June 1945 on nuclear power and nuclenr weapons, neither of which appears to be easily accessible in Britain.

'The book throws some fresh light on the struggle in the United States to free nuclear energy from military control and to avoid the domination of nuclear research by secrecy or security restrictions. It also illuminates tho initial approaches to the international control of nuclear activities, but its chief value seems to lie in pointing out how much is demanded of scientists who are seriously concerned about the social consequenees of their work. To influence public policy offectively requires much more than goodwill, more even than clear understanding of the scientific and technical factors and thoir implications; it demands an understanding of the political process also and a rendiness to accept the conditions of effective participation. Mrs. Smith might perhaps have told her story more briefly and effectivoly, but at loast in conclusion she puts the issues and the price demanded succinctly and unmistalkably. R. Brightman

\section{PHYSICAL PRINCIPLES OF MAGNETISM}

The Physical Principles of Magnetism

By Prof. Allan H. Morrish. (Wilcy Series on the Science and Technology of Materials.) Pp. xy +680 . (New York and London: John Wiley and Sons, Inc., 1965.) $125 s$. $7 \begin{gathered}\text { HE magnetic proporties of materials is a field of } \\ \text { investigation in which many important and signi- }\end{gathered}$ 25 years. The unified aceount of magnotic phonomena in solids, which The Physical Principles of Magnetism provides, will therefore be welcomed by the increasing number of physicists and engineers who wish to acquire a comprehonsive knowledge of this branch of solid-state physics.

After an introductory chapter on classical electromagnetic theory, the first portion of the book deals mainly with paramagnetic systems. This is followed by a chapter on the magnetic properties of an electron gas, and accounts are given here of such topics as Pauli spin paramagnetism, the de Haas-van Alphen effect and the magnetic propertios of superconductors. The remainder of the book is devoted to an extensive discussion of magnetic materials in which the magnetic carriers are strongly coupled by exchange forces. Forromagnetics, antiferromagnetics and ferrimagnetics are each treated separately and in considerable detail.

The author has dealt with the subject mainly in a theorotical way. Experimental results and data are, however, included to illustrate and compare with the theory, but experimental methods and techniques are rarely described. Wherever possible, phenomenological approaches have been adopted to the topics discussed. Thus, for example, magnetic resonance is explained in terms of a precessing dipole, while the Weiss molecular field is used as a basis for the theory of ferromagnetism. For a complete understanding of a number of sections of the book, however, an aequaintance with solid-state theory and a good working knowlcdge of quantum mechanics are essential. 'The subject matter is presented in a clear and coherent manner, and the text is adequately illustrated with well-prepared diagrams. Since this is a book devoted solely to magnetism, the use of c.g.s. units is perhaps appropriate, since it is still fashionable for experimentalists to use these units when quoting their results. For the bonofit of readers who are familiar only with the M.K.s. system, a conversion table is provided in an appendix. A useful feature of the book is the inclusion of a 